\title{
Numerical analysis on seismic behavior of a novel sandwich wall system
}

\author{
Zhao-yan Tian ${ }^{1}$ and Qun Xie ${ }^{1 *}$ \\ ${ }^{1}$ School of Civil Engineering and Architecture, University of Jinan, Jinan, Shandong, 250022, China
}

\begin{abstract}
Concrete sandwich panel is a kind of building element with the characteristics of light weight, high strength, suitability for standardized production, meanwhile it has the multi-function of heat preservation and sound insulation which can be used not only as enclosure components, but also as structural components for multi-story residential buildings. A novel sandwich wall system has been presented in this work with an innovative design concept. Compared with traditional steel wire sandwich panel, this sandwich panel wall system has unique features such as prefabricated steel system, core column with spiral stirrup, foamed concrete as insulation layer. This wall system also meets the national policy requirements in energy-saving and has potential application and development prospects. In this paper, Finite element method is used to simulate and analyze the seismic performance of this new sandwich wall panel. The results show that the panel with 3D steel wire has greater stiffness and better earthquake resistance than panel with planar steel wire mesh.
\end{abstract}

\section{Introduction}

The traditional steel wire concrete sandwich panel system is a light composite structure which consists of concrete layer on both sides and light material fill-up layer inside. The panel has the functions of heat preservation, moisture-proof and sound insulation [1-5]. The steel wire mesh is set in transverse and longitudinal intersection, and the transverse steel truss throughout the insulation layer to connect the two concrete layers which is shown in figure 1[6-9]. Steel wire sandwich wall panels first appeared in North America in the 1960s, and have been applied to partitions and exterior walls of residential, school and office buildings [10]. A novel sandwich wall panel has been presented in this work whose insulation layer consists of prefabricated foam concrete blocks with function of heat preservation. In order to investigate the structural behavior of such sandwich panel, numerical analysis has been carried out and the results have been presented as follow.

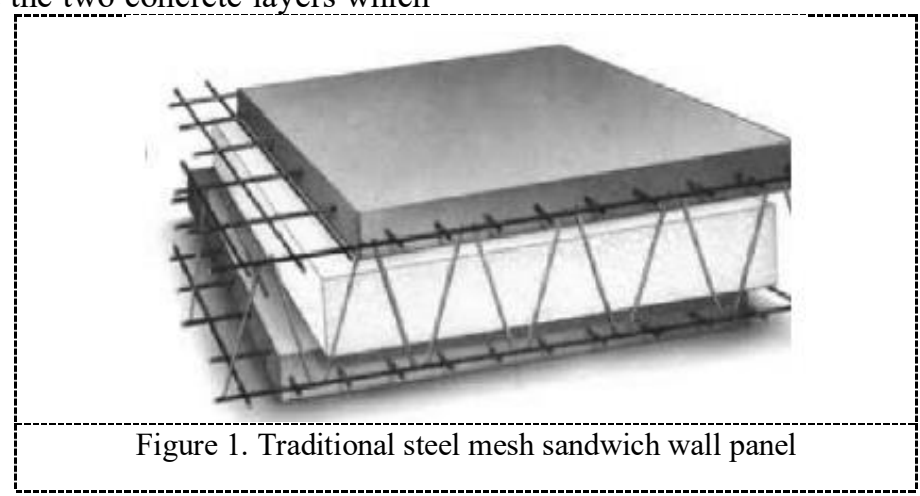

\section{Numerical simulation and analysis}

In order to study the seismic behavior of this sandwich wall panel, Finite element software ABAQUS is adopted to simulate the structural response of two types of panel subjected to earthquake.

\subsection{Model Information}

2 panels numbered of $\mathrm{W} 1$ and $\mathrm{W} 2$ are considered in the simulation, planar steel wire mesh is used in concrete layer of panel W1 and 3D steel wire in concrete layer of panel W2, respectively. The detailed information of panels are shown in Table 1 and the cross-section of $\mathrm{W} 1$ and W2 is shown in Figure $2 \& 3$.

\footnotetext{
*Corresponding author's e-mail: cea_xieq@ujn.edu.cn
} 
Table 1. Specimen information

\begin{tabular}{lccllllll}
\hline No. & $\begin{array}{c}\text { Section } \\
\text { height }\end{array}$ & $\begin{array}{c}\text { Panel } \\
\text { height }\end{array}$ & $\begin{array}{c}\text { Layer } \\
\text { thickness }\end{array}$ & $\begin{array}{c}\text { Insulation } \\
\text { thickness }\end{array}$ & $\begin{array}{c}\text { Type of } \\
\text { steel wire } \\
\text { mesh }\end{array}$ & $\begin{array}{c}\text { Diameter } \\
\text { of steel } \\
\text { wire }\end{array}$ & $\begin{array}{c}\text { Diameter of } \\
\text { spiral stirrup }\end{array}$ & $\begin{array}{c}\text { Diameter of } \\
\text { longitudinal } \\
\text { rebar }\end{array}$ \\
\hline W1 & $1300 \mathrm{~mm}$ & $2400 \mathrm{~mm}$ & $25 \mathrm{~mm}$ & $60 \mathrm{~mm}$ & Planar & $3 \mathrm{~mm}$ & $4 \mathrm{~mm}$ & $8 \mathrm{~mm}$ \\
W2 & $1300 \mathrm{~mm}$ & $2400 \mathrm{~mm}$ & $40 \mathrm{~mm}$ & $60 \mathrm{~mm}$ & $3 \mathrm{D}$ & $2 \mathrm{~mm}$ & $4 \mathrm{~mm}$ & $8 \mathrm{~mm}$ \\
\hline
\end{tabular}
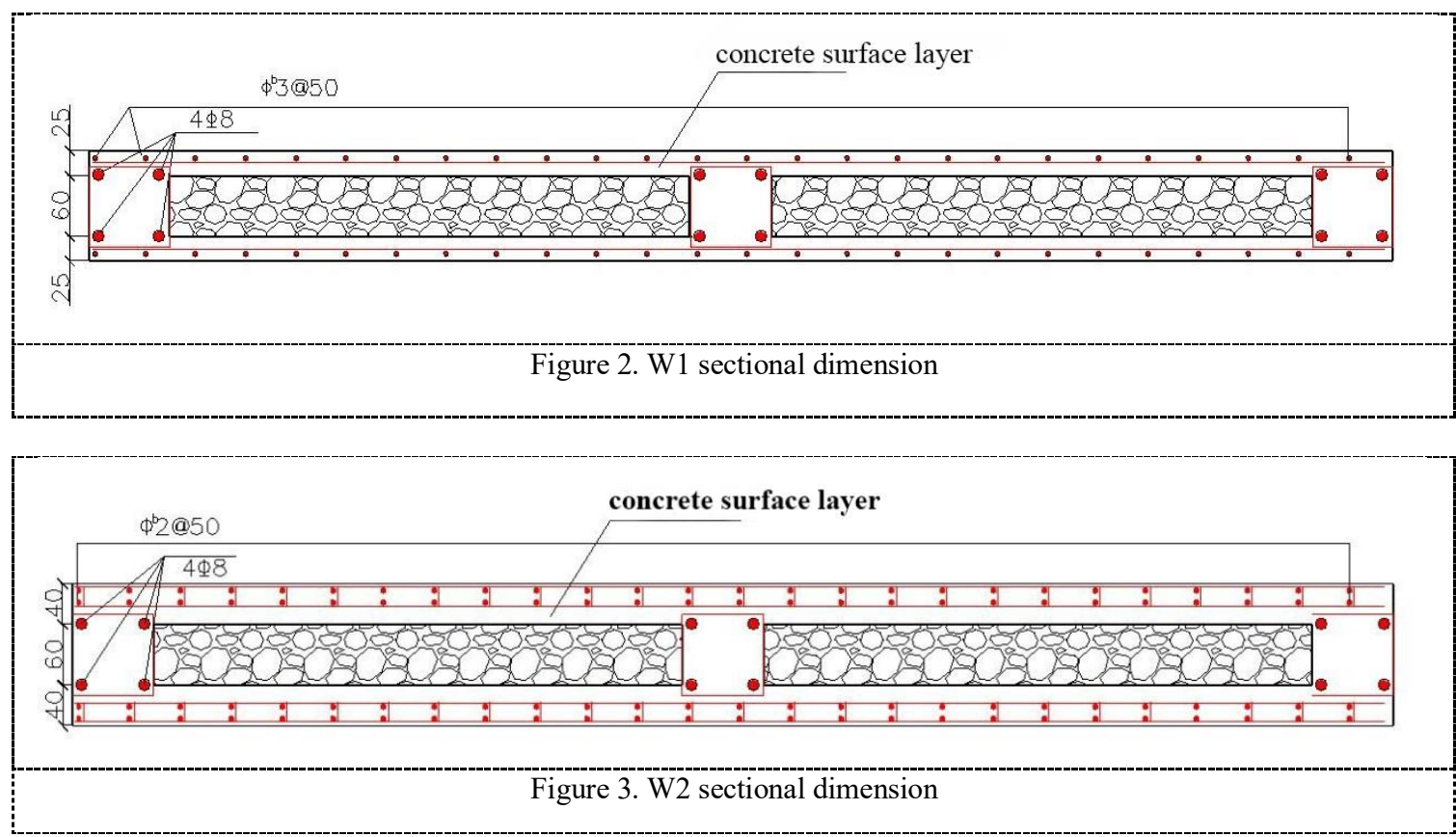

\subsection{Model information}

3D solid element is adopted to simulate concrete in panel. The reinforcing bar, steel wire mesh, spiral stirrup in core column are stimulated with solid element. Element size of concrete panel is $50 \mathrm{~mm}$, and element size of steel bar element are $10 \mathrm{~mm}$. A constant compression is applied on the top of model to simulate the axial action of wall pane. The constraint conditions of model bottom are fixed in three directions. The finite element model is shown in figure 4,5 .

\subsection{Analysis results}

According to the analysis results, the maximum lateral strength of $\mathrm{W} 1$ and $\mathrm{W} 2$ is $276 \mathrm{kN}$ and $289 \mathrm{kN}$ respectively, and the corresponding lateral displacement at panel top is $17.2 \mathrm{~mm}$ and $21 \mathrm{~mm}$ respectively. In the process of loading, both reinforcement and concrete are in the elastic stage, and the bearing capacity develops linearly. Under the same horizontal displacement, the development of bearing capacity of panel W2 is faster than that of W1, and the strength reduction degree of W2 is obviously less than that of panel W1. And the deformation of the two specimens is relatively small which mainly concentrates at the bottom flange of model. The steel stress contour has been shown in figure 6 . 

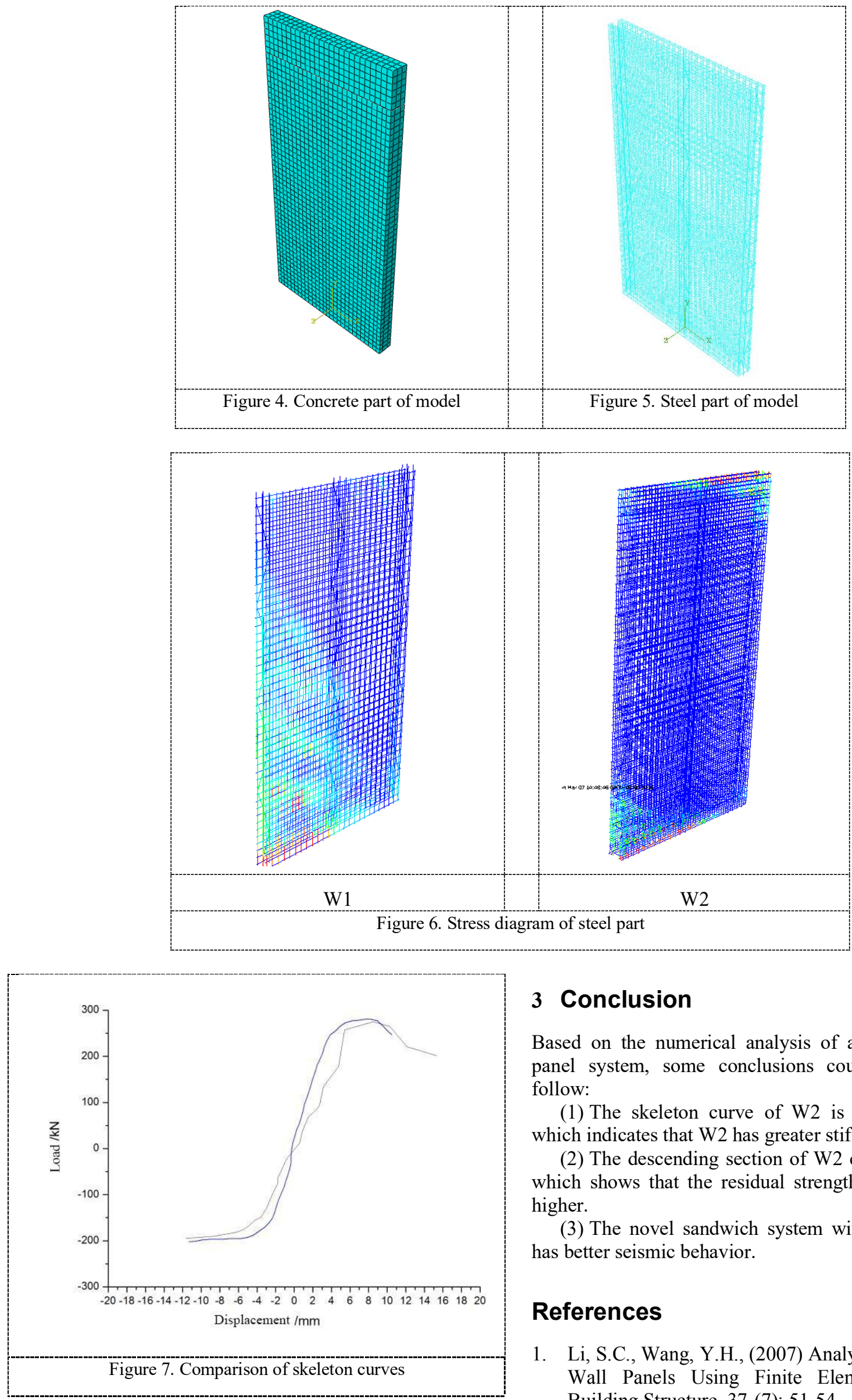

\section{Conclusion}

Based on the numerical analysis of a novel sandwich panel system, some conclusions could be drawn as follow:

(1) The skeleton curve of W2 is steeper than W1 which indicates that $\mathrm{W} 2$ has greater stiffness.

(2) The descending section of W2 curve is smoother which shows that the residual strength of W2 is much higher.

(3) The novel sandwich system with 3D steel mesh has better seismic behavior.

\section{References}

1. Li, S.C., Wang, Y.H., (2007) Analysis on Composite Wall Panels Using Finite Element Method. J. Building Structure, 37-(7): 51-54. 
2. Ali, S., Joesf, H., Michael H. (2014) An analytical model for sandwich panels made of textilereinforced concrete. J. Construction and Building Materials, 64: 451-459.

3. Junsun, K. (2015) Composite and non-composites behaviors of foam-insulated concrete sandwich panels. J. Composites: Part B, 68: 153-161.

4. Zhang, T.Y., Zhang, X.H., Yu, Q.R. (2001) Study on the form of structure layer in sandwich wall panel. J. Journal of Xi'an University of Architecture \& technology, 23(1): 10-13.

5. Sharaf, T., Shawkat, W., \& Fam, A. (2010) Structural performance of sandwich wall panels with different foam core densities in one-way bending. J. Journal of Composite Materials, 44(19): 2249-2263.

6. Yang, J. G., Wang, G., \& Ding, K.W. (2013) Thermal performance test of the new sandwich insulation composite wall panels. J. Advanced Materials Research, 676, 22-26.

7. Li, C.G., Yang, J., Design, construction and quality control of precast prestressed concrete sandwich wall panels. J. Building Technique Development, 38(10): 1-3.

8. Mohamad, N., Omar, W., \& Abdullah, R. (2012) Structural behaviour of precast lightweight foamed concrete sandwich panel as a load bearing wall. J. International Journal of Sustainable Development, 5(3): 49-58.

9. Li, J.Y., Wang, Y. \& Liu. N. (2010) Finite element analysis of displacement of complex wall cladding in horizontal load. J. Industrial Construction, 40(12): 87-89.

10. Lee B.J., Stephen P. (2008) Experimental evaluation of precast, prestressed concrete, three-wythe sandwich wall panels. J. PCI Journal, 53(2): 95-115. 